\title{
Study of in vitro and in vivo dissolution of theophylline from film-coated pellets
}

\author{
Zs. Muskóa ${ }^{\mathrm{a}}$, K. Pintye-Hódi ${ }^{\mathrm{a}, *}$, R. Gáspár ${ }^{\mathrm{b}}$, J. Pintye $^{\mathrm{c}}$, P. Szabó-Révész ${ }^{\mathrm{a}}$, I. Erôs ${ }^{\mathrm{a}}$, G. Falkay $^{\mathrm{b}}$ \\ ${ }^{a}$ Department of Pharmaceutical Technology, University of Szeged, Hungary \\ ${ }^{\mathrm{b}}$ Department of Farmacodynamics and Biopharmacy, University of Szeged, Hungary \\ ${ }^{\mathrm{c}} \mathrm{Dr}$ Diósszilágyi Sámuel Hospital, Makó, Hungary
}

Received 29 March 2000, accepted in revised form 30 October 2000

\begin{abstract}
Tests were performed on the influence of polymer coating films on the rates and the extents of in vitro and in vivo liberation of theophylline from pellets. Uncoated and coated pellets were used in the experiments. The coating material was Eudragit L; The film thickness was varied. The in vivo liberation of theophylline was studied in rabbits. The serum level of the released drug measured with a TDX Analyser. No appreciable difference was observed between the uncoated and the coated pellets as concern the maximum release data, but a significant shift was found in $\mathrm{t}_{\max }$ for Eudragit L coated pellets. (C) 2001 Elsevier Science B.V. All rights reserved.
\end{abstract}

Keywords: Theophylline; Film coated pellet; Eudragit L; In vitro dissolution; In vivo dissolution; Plasma level

\section{Introduction}

Solid dosage forms play an important role in pharmaceutical production. Studies aimed at a better understanding of factors acting on pellets and pellet-based tablets are therefore of primary concern [1,2].

Film-coated solid dosage forms, e.g. pellets and tablets, are currently of increasing importance. An appropriate coating fluid applied to a pellet surface produces a macromolecular film coat, the properties of which will influence the pellet parameters and the liberation of drug from the pellets and from the tablets manufactured from them [3-7]. The thickness of this film influences the rate of dissolution of the drug. For this reason, the film thickness is an important factor.

Dissolution tests are performed under in vitro conditions, but to optimize a dosage form the in vivo investigations are also necessary [8-12].

In this work, an enteric polymer was studied. Theophylline was the chosen drug. The serum theophylline levels comprise an individual monitoring tool in theophylline dosing. The dosing of theophylline is complicated by the extensive variation in bioavailability among patients.

\footnotetext{
* Corresponding author. H-6720, Eötvös str. 6, Szeged, Hungary. Tel: +36-62-545-576.

E-mail address: hodi@pharma.szote.u-szeged.hu (K. Pintye-Hódi).
}

Theophylline has a relatively low therapeutic index. Appropriate dosing is therefore critical, and should be based on patient response and tolerance, pulmonary function, and serum theophylline concentrations [13]. In general, therapeutic serum theophylline concentrations range from 5 to $15 \mu \mathrm{g} / \mathrm{ml}$. Toxicity usually appears at concentrations above $20 \mu \mathrm{g} / \mathrm{ml}$. Peak theophylline levels are good correlated with efficacy and toxicity $[14,15]$. The recommended time to obtain a peak serum theophylline concentration level after an initial intravenous aminophylline dose is $30 \mathrm{~min}$ after completion of the loading dose [16]. For an orally administered theophylline solution or uncoated tablet and extended-release theophylline preparations, $1-2 \mathrm{~h}$ and $3-12 \mathrm{~h}$ after the initial dose, respectively, are recommended $[13,14]$. The manufacturers of once-aday theophylline preparations recommend that peak theophylline serum concentration levels should be measured at 8-12 h after a dose of theophylline, respectively. Trough levels may be obtained just prior to the next dose of theophylline, but these levels do not generally provide any clinically relevant information. On each occasion, blood samples should be obtained during the same dosing inter$\mathrm{val}$, in order to minimize the circadian variation in theophylline absorption. 


\section{Experimental}

\subsection{Materials}

\subsubsection{Core}

For the Theophylline pellets, the following materials were used: Theophylline (Theophyllinum, Ph. Eur. 3) 200 g, mannitol (Mannitum, Ph. Eur. 3) 300 g, Vitacel A $300^{\circledR}$ (Rettenmaier \& Söhne GmbH \& Co., Ellwangen-Holzmühle, Germany) 500 g, Kollidon VA $64^{\circledR}$ (BASF Aktiengesellschaft $\mathrm{GmbH}$, Ludwigshafen, Germany) $57 \mathrm{~g}$, and saccharose (Saccharosum, Ph. Eur. 3) 450 g, corn starch (Ph. Eur. 3) 170 g, silica, colloidal anhydrous (Ph. Eur. 3) $11 \mathrm{~g}$.

\subsubsection{Coating material}

Eudragit L 100-55 ${ }^{\circledR}$ (Röhm-Pharma GmbH Chemische Fabrik, Darmstadt, Germany) An anionic copolymer of methacrylic acid and acrylate with an average molecular mass of 250000 . It is a fine white powder that also contains sodium dodecylsulfate $(0.7 \%)$ and polysorbate $80(2.3 \%)$. Eudragit is soluble in organic solvents. In water, it does not dissolve, but is dispersed [17]. The film formed from a water dispersion of Eudragit L 100-55 starts to dissolve at pH 5.5, which makes it suitable for enteric coatings.

\subsection{Methods}

\subsubsection{Preparation of pellets}

The core material was placed in the working space of a centrifugal granulator (Freund CF-360, Japan). Pelletizing was performed at a rotor speed of $200 \mathrm{rev} . / \mathrm{min}$, with a granulating fluid feed rate of $20 \mathrm{rev} . / \mathrm{min}$ ( = $20 \mathrm{ml} / \mathrm{min}$ ), and an atomizing air pressure of 4,6 atm, the build-up powder being introduced discontinuously, at $20 \mathrm{rev} . / \mathrm{min}$, and at an inlet and outlet air temperature of $40^{\circ} \mathrm{C}$.

\subsubsection{Coating process}

A Strea-1 fluid bed apparatus was used with a Wurster container (Niro-Aeromatic, Bubendorf, Switzerland). Coating was performed at an atomizing pressure of 2 bar, a blowout pressure of 4.2 bar, a coating fluid rate of $5 \mathrm{ml} / \mathrm{min}$, and a drying temperature of $40^{\circ} \mathrm{C}$.

\subsubsection{In vitro dissolution of the active agent}

The rotating basket method with half change [18] was used. The test was started with artificial gastric fluid, half of which was changed to intestinal fluid every hour. In this way, the $\mathrm{pH}$ changes were similar to those seen in the digestive tract.

2.2.3.1. Test conditions. Apparatus: Pharma Test PTW 2 with six measuring sites and microprocessor control (Pharma Test GmbH, Germany). Rotation speed: 50 rev./ min. Temperature: $37 \pm 1^{\circ} \mathrm{C}$. Dissolution medium volume: $900 \mathrm{ml}$. Sampling time: 1, 2, 3, 4, 5, 6 and $7 \mathrm{~h}$.
Measurement: with a UV spectrophotometer (Spektromom 195D, MOM, Hungary) at $268 \mathrm{~nm}$ for $\mathrm{pH}=1.18-1.91$, at $270 \mathrm{~nm}$ for $\mathrm{pH}=6.24-6.92$, and at $271 \mathrm{~nm}$ for $\mathrm{pH}=7.22$ 7.51.

Computerized data processing: SPSS for Windows 6.1.2. Copyright (C) SPSS Inc., USA

\subsubsection{In vivo experiments}

New-Zealand white rabbits (2500-3000 g) were treated orally with gelatine capsules containing $0.2 \mathrm{~g}$ theophylline pellets (dosage: $10 \mathrm{mg} / \mathrm{kg}$ ). The animals were fasted for $12 \mathrm{~h}$ before the experiments. The capsules were introduced directly into the oesophagus and washed in with $5 \mathrm{ml}$ of distilled water in order to avoid possible damage caused by chewing. Blood samples were collected from ear veins $1,2,3,4,5,6,8,12$ and $24 \mathrm{~h}$ after the oral administration. The samples were centrifuged at $14500 \mathrm{rev} . / \mathrm{min}$ with a TDX centrifuge (Abbott Laboratories, Germany) and plasmas were stored at $-20^{\circ} \mathrm{C}$ for further analytical determination.

The centrifuged plasma samples were measured with a TDX Analyzer (Automated Fluorescence Polarization Analyzer No. 9520-04, Abbott Laboratories, Germany). Minimum sample volume required in sample well: $50 \mu \mathrm{l}$. For validation of the assay, control samples containing human blood components were used.

\section{Results and discussion}

The disintegration of the uncoated pellets in the in vitro test was complete in $5 \mathrm{~min}$, which is in accordance with the release of $35 \%$ of the agent in the first 5 min (Fig. 1). From the 5 th min on, the dissolution curve declined. The dissolution rate became lower and the amount of agent liberated progressively fell off up to the end of the investigation. The linear model reflects the dissolution of the active agent $(P<0.05 ; r=0.953)$.

For the coated pellets, the dissolution profiles (Fig. 2) are

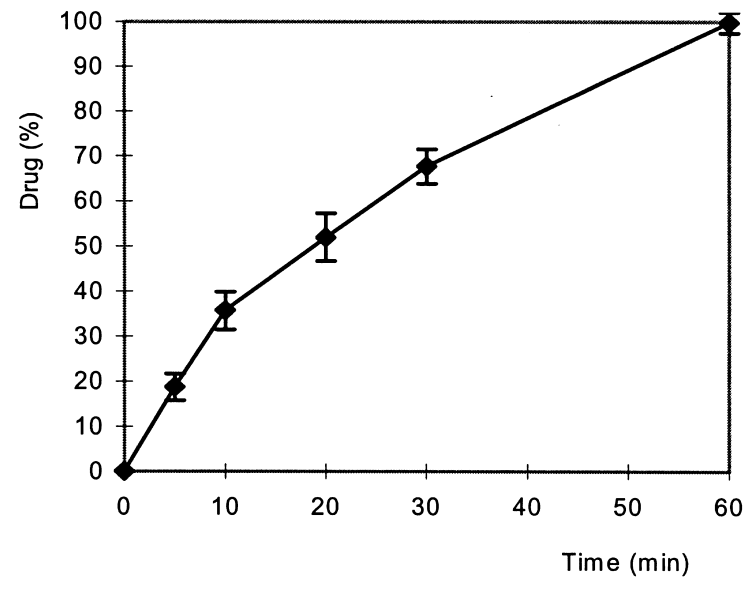

Fig. 1. Dissolution of theophylline from uncoated pellet. 


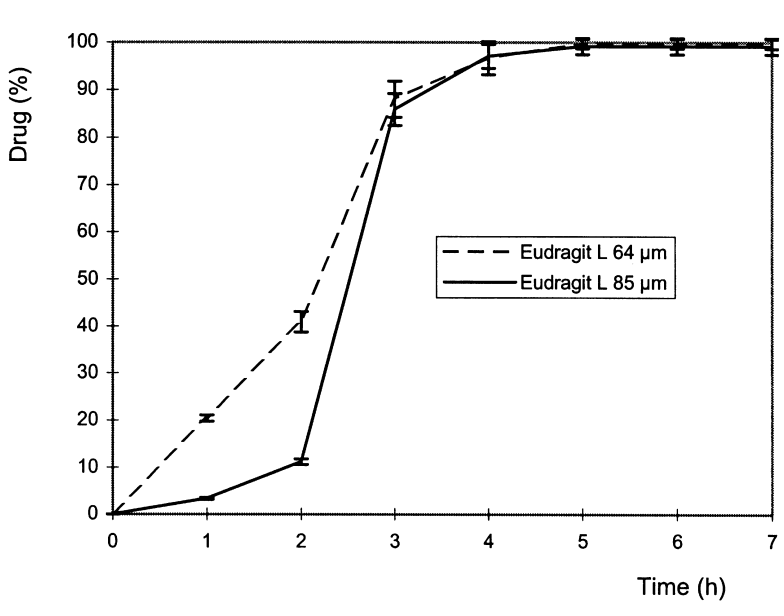

Fig. 2. Dissolution of theophylline from coated pellets.

sigmoidal in both cases. Theophylline initially dissolves at a low rate, predominantly by diffusion through the coating and its possible discontinuities. Between 2 and $3 \mathrm{~h}$, however, when the $\mathrm{pH}$ of the dissolution medium reaches the level critical for the coating $(\mathrm{pH}=5.5)$, the film starts to dissolve, thereby increasing the diffusion. Such a curve is also typical for retard forms, but the adequate plasma level will develop later, after the passage of the pellets into the intestine. The mathematical evaluation of the dissolution process was studied according to Rosin-Rammler-Sperling-Bennett-Weibull (RRSBW) distribution and the characteristical dissolution time $\left(\mathrm{t}_{63.2 \%}\right)$ was determined [19]. Significant difference was found; $\mathrm{t}_{63.2 \%}$ was $99.04 \mathrm{~min}$ $(P<0.05, r=0.9930)$ in the case of $64 \mu \mathrm{m}$ in film thickness and it was $171.74 \min (P<0.05, r=0.9610)$ at the 85 $\mu \mathrm{m}$ in thickness.

The plasma level of theophylline released from uncovered pellets rose quickly and the maximum concentration (14.36 mg/l) (Fig. 3) was reached by $2 \mathrm{~h}$ after administration. The changes in concentration between 2 and $4 \mathrm{~h}$ was not significant. After $3 \mathrm{~h}$, the theophylline plasma level decreased. There was a major fall in plasma concentration

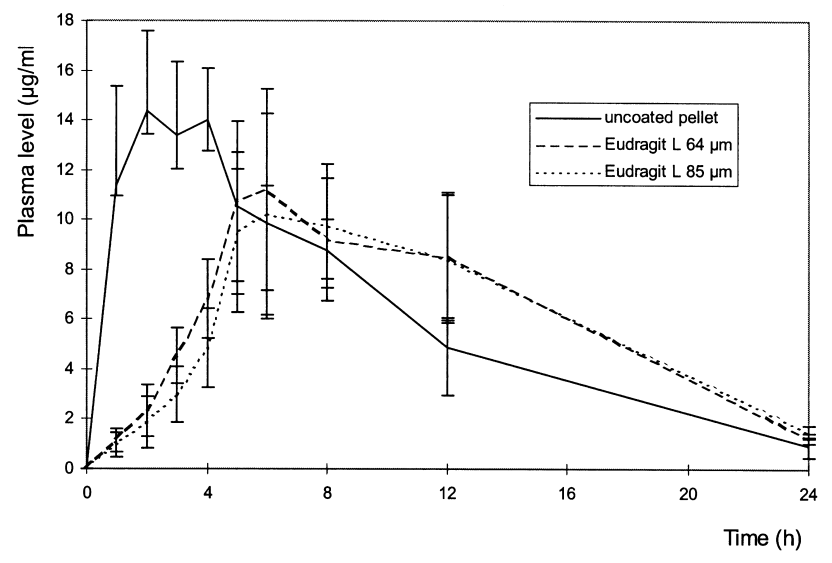

Fig. 3. Plasma level of theophylline after administration in rabbits.
Table 1

Data of in vivo tests

\begin{tabular}{lccc}
\hline & \multicolumn{2}{l}{ Coating film } \\
\cline { 3 - 4 } & No coating & Eudragit L 64 $\mu \mathrm{m}$ & Eudragit L 85 $\mu \mathrm{m}$ \\
\hline Total area & 148.7 & 145.6 & 141.3 \\
$\mathrm{t}_{\max }(\mathrm{h})$ & 2.000 & 6.000 & 6.000 \\
$\mathrm{c}_{\max }(\mu \mathrm{g} / \mathrm{ml})$ & 14.36 & 11.22 & 10.24 \\
\hline
\end{tabular}

between 4 and $12 \mathrm{~h}$. The rate of decline moderated between 12 and $24 \mathrm{~h}$.

The blood concentration of theophylline released from pellets covered with Eudragit L $(64 \mu \mathrm{m})$ reached the maximum value $(11.22 \mathrm{mg} / \mathrm{l})$ at $6 \mathrm{~h}$ (Table 1$)$. The decrease in theophylline concentration occured at a lower rate than that for the uncoated pellets.

Similarly as for Eudragit L $(64 \mu \mathrm{m})$, the theophylline released from pellets coated with Eudragit $\mathrm{L}(85 \mu \mathrm{m})$ reached its maximum concentration $(10.24 \mathrm{mg} / \mathrm{l})$ at $6 \mathrm{~h}$ and the decrease in theophylline concentration was also similar to that for Eudragit L $(64 \mu \mathrm{m})$. The AUC values were calculated (Table 1) and mathematical evaluation (paired $t$-test) was performed. The difference in the AUC values was not significant.

Finally, it can be concluded, that in the in vivo studies, the dissolution can be characterized by the value of the maximum concentration $\left(c_{\max }\right)$ and the time necessary to reach this $\left(t_{\max }\right)$. There was no great difference in the maximum values (all the pellets gave $c_{\max }>10 \mathrm{mg} / \mathrm{l}$ ) between the uncoated and the Eudragit L-coated pellets, but a significant shift in $\mathrm{t}_{\max }$ was found for both Eudragit-coated pellets $(P<0.05, r=0.9992)$. The difference was $4 \mathrm{~h}$ as compared with the uncoated preparation. This result exhibits a relationship to the difference between the in vitro dissolutions ( 3 h), which confirms the reliability of the in vitro dissolution method. The slower decreases in theophylline concentration in the cases of the Eudragit $\mathrm{L}(64 \mu \mathrm{m})$ and Eudragit L (85 $\mu \mathrm{m})$ films demonstrate the effectiveness of the enteric coating process.

\section{References}

[1] A.E. Lundqvist, F. Podczeck, J.M. Newton, Compaction of, and drug release from, coated drug pellets mixed with other pellets, Eur. J. Pharm. Biopharm. 46 (1998) 369-379.

[2] K.G. Majid, J.B. Zhu, Ibuprophen release kinetics from controlledrelease tablets granulated with aqueous polymeric dispersion of ethylcellulose II: influence of several parameters and coexcipients, J. Control Release 56 (1998) 127-134.

[3] B.C. Lippold, W. Gunder, B.H. Lippold, Drug release from diffusion pellets coated with the aqueous ethylcellulose dispersion Aquacoat ECD-30 and 20\% dibutyl sebacate as plasticizer: partition mechanism and pore diffusion, Eur. J. Pharm. Biopharm. 47 (1999) 27-32.

[4] C. Vecchio, F. Fabiani, M.E. Sangalli, L. Zema, A. Gazzaniga, Rotary tangential spray technique for aqueous film coating of indobufen pellets, Drug Dev. Ind. Pharm. 24 (1998) 269-274.

[5] A. Gursoy, D. Karakus, I. Okar, Polymers for sustained release formu- 
lations of dipyridamole-alginate microspheres and tabletted microspheres, J Microencapsul. 16 (1999) 439-452.

[6] E.N. Griffin, P.J. Niebergall, Release kinetics of a controlled-release multiparticulate dosage from prepared using a hot-melt fluid bed coating method, Pharm. Dev. Technol. 4 (1999) 117-124.

[7] M.L. Lorenzo-Lamosa, C. Remunan-Lopez, J.L. Vila-Jato, M.J. Alonso, Design of microencapsulated chitosan microspheres for colonic drug delivery, J. Control Release 52 (1998) 109-118.

[8] O.A. Lake, M. Olling, D.M. Barends, In vitro/in vivo correlations of data of carbamazepine immediate release tablets with pharmacokinetic data obtained in healthy volunteers, Eur. J. Pharm. Biopharm. 48 (1999) 13-19.

[9] S. Sabnis, C.M. Adeyeye, Controlled-release hydrophilic tablets for individualized theophylline therapy, Drug Dev. Ind. Pharm. 25 (1999) 187-196.

[10] V. Pillay, R. Fassihi, Evaluation and comparison of dissolution data derived from different modified release dosage forms: an alternative method, J. Control Release 55 (1998) 45-55.

[11] A. Von-Nieciecki, W.S. Fuchs, G. Pabst, M. Müller, C. Dilger, S. Gay, A. Laicher, F. Stanislaus:, In vivo verification of in vitro release specifications of a theophylline sustained-release preparation, Arzneimittelforschung 48 (1998) 580-583.

[12] W.S. Fuchs, A. Von-Nieciecki, K.H. Molz, G. Popescu, A. Weil, M.F. Barkworth, S. Gay, A. Laicher, F. Stanislaus, Effect of gallbladder contraction induced cholagogia on the pharmacokinetic profile of a sustained-release theophylline formulation, Arzneimittelforschung 46 (1996) 1120-1126.

[13] American Society of Hospital Pharmacists, AHFS: American Hospital Formulary Service Drug Information 90, American Society of
Hospital Pharmacists, Bethesda, MD, 1990 in Micromedex, Inc., Englewood, Co., Vol. 101 Exp. 30/09/99, Topic: Theophylline monitoring serum levels.

[14] L. Hendeles, M. Massanari, M. Weinberger, Theophilline, in: W.E. Evans, J.J. Schentag, W.J. Jusko (Eds.), Appilied Pharmacokinetics, 2nd edition, Applied Therapeutics, Spokane, WA, 1986 in Micromedex, Inc., Englewood, Co., Vol 101 Exp. 30/09/99, Topic: Theophylline monitoring serum levels.

[15] H.W. Kelly, G.D. Smith, Asthma, in: L.Y. Young, M.A. KodaKimble (Eds.), Applied Therapeutics The Clinical Use of Drugs, 4th edition, Applied Therapeutics Inc, Vancouver, WA, 1988 in Micromedex, Inc., Englewood, Co., Vol. 101 Exp. 30/09/99, Topic: Theophylline monitoring serum levels.

[16] A. Anon, Theophylline intravenous labeling guidelines. Memorandum from the Department of Health and Human Services, Department of Health and Human Services, Washingon, DC, 1995 September 1, (1995) in Micromedex, Inc., Englewood, Co., Vol101 Exp. 30/09/99, Topic: Theophylline monitoring serum levels.

[17] K. Lehmann, Practical course in film coating of pharmaceutical dosage forms with EUDRAGIT ${ }^{\circledR}$, Röhm GmbH, Pharma Polymers, Darmstadt, 1999, pp. 26-27.

[18] K. Münzel, Die 'Zerfallsprüfung' einzeldosierter oraler Arzneiformen mit verlängerter Wirkung in vitro, Archiv. Pharmazie 293/65 (1960) 766-785.

[19] Zs. Muskó, K. Pintye-Hódi, P. Szabó-Révész, P. Kása Jr, I. Erôs, D. Deák, Measurment of film thickness on the surface of coated pellets and its influence on the drug dissolution rate, Pharmazie 55 (2000) 465-466. 